\title{
Brachial Vein
}

National Cancer Institute

\section{Source}

National Cancer Institute. Brachial Vein. NCI Thesaurus. Code C12883.

Deep vein of the upper arm that forms at the junction of the radial and ulnar veins and ends at the inferior border of the teres major. 